\title{
Allosteric control of Escherichia coli rRNA promoter complexes by DksA
}

\author{
Steven T. Rutherford, Courtney L. Villers, Jeong-Hyun Lee, Wilma Ross, and Richard L. Gourse ${ }^{1}$ \\ Department of Bacteriology, University of Wisconsin at Madison, Madison, Wisconsin 53706, USA
}

\begin{abstract}
The Escherichia coli DksA protein inserts into the RNA polymerase (RNAP) secondary channel, modifying the transcription initiation complex so that promoters with specific kinetic characteristics are regulated by changes in the concentrations of ppGpp and NTPs. We used footprinting assays to determine the specific kinetic intermediate, $\mathbf{R P}_{\mathrm{I}}$, on which DksA acts. Genetic approaches identified substitutions in the RNAP switch regions, bridge helix, and trigger loop that mimicked, reduced, or enhanced DksA function on rRNA promoters. Our results indicate that DksA binding in the secondary channel of $\mathbf{R P}_{\mathrm{I}}$ disrupts interactions with promoter DNA at least $25 \AA$ away, between positions -6 and +6 (the transcription start site is +1 ). We propose a working model in which the trigger loop and bridge helix transmit effects of DksA to the switch region(s), allosterically affecting switch residues that control clamp opening/closing and/or that interact directly with promoter DNA. DksA thus inhibits the transition to $\mathrm{RP}_{\mathrm{I}}$. Our results illustrate in mechanistic terms how transcription factors can regulate initiation promoter-specifically without interacting directly with DNA.
\end{abstract}

[Keywords: RNA polymerase; promoter; DksA; ppGpp; transcription initiation; ribosome synthesis]

Supplemental material is available at http://www.genesdev.org.

Received September 25, 2008; revised version accepted December 1, 2008.

DksA, ppGpp, and NTPs work together to regulate rRNA synthesis in Escherichia coli (Paul et al. 2004). DksA concentrations are relatively constant (Rutherford et al. 2007), but ppGpp and NTP concentrations vary dramatically with nutrient availability (Murray et al. 2003). Inactivation of the $d k s A$ gene derepresses rRNA transcription, uncoupling ribosome production from the cellular demand for protein synthesis, because direct modification of RNA polymerase (RNAP) by DksA is needed for changes in the concentrations of ppGpp and NTPs to exert effects on the transcription initiation complex (Paul et al. 2004).

The mechanism of DksA action remains unclear. Unlike conventional regulators of transcription initiation, DksA does not bind to DNA but instead interacts directly with RNAP (Paul et al. 2004; Perederina et al. 2004). Biochemical studies and structural similarities between DksA and the transcription elongation factors GreA and GreB suggest that DksA binds in the RNAP secondary channel (Opalka et al. 2003; Perederina et al. 2004; S.T. Rutherford, I. Toulokhonov, C.E. Vrentas, W. Ross, and R.L. Gourse, unpubl.), but there is no structure of DksA bound to RNAP, and the precise interactions between RNAP and DksA have yet to be defined.

${ }^{1}$ Corresponding author.

E-MAIL rgourse@bact.wisc.edu; FAX (608) 262-9865.

Article is online at http://www.genesdev.org/cgi/doi/10.1101/gad.1745409.
Because DksA binds RNAP instead of a specific DNA sequence, it has the potential to affect all promoter complexes. Consistent with this prediction, DksA decreases the lifetimes of complexes formed by all promoters tested to date (Paul et al. 2004, 2005; Rutherford et al. 2007). However, DksA directly affects transcriptional output only from a subset of promoters, including many needed for the synthesis of ribosomes, virulence, membrane stress responses, and amino acid biosynthesis and transport (for review, see Haugen et al. 2008). The promoter-specific effects of DksA on transcriptional output are dictated by the intrinsic kinetic properties of different promoters (Haugen et al. 2008).

Transcription begins with binding of RNAP holoenzyme (subunit composition $\alpha_{2} \beta \beta^{\prime} \omega \sigma$ ) to the promoter, forming an initial complex in which the DNA strands remain paired (closed complex, $\mathrm{RP}_{\mathrm{C}}$ ) (Fig. 1A). This complex undergoes a series of conformational changes in both the DNA and RNAP that ultimately result in formation of a transcriptionally competent open complex $\left(\mathrm{RP}_{\mathrm{O}}\right)$ in which the DNA strands are separated from approximately -11 to approximately +3 (Haugen et al. 2008 and references within). At least one additional kinetically significant intermediate (referred to here as $\mathrm{RP}_{\mathrm{I}}$ ) has been identified between $\mathrm{RP}_{\mathrm{C}}$ and $\mathrm{RP}_{\mathrm{O}}$ (Fig. 1A; Saecker et al. 2002; for review, see Haugen et al. 2008). Transcription initiation likely proceeds through the same series of intermediates at all promoters, but the fractional occupancy of these intermediates at equilibrium differs at different promoters. 

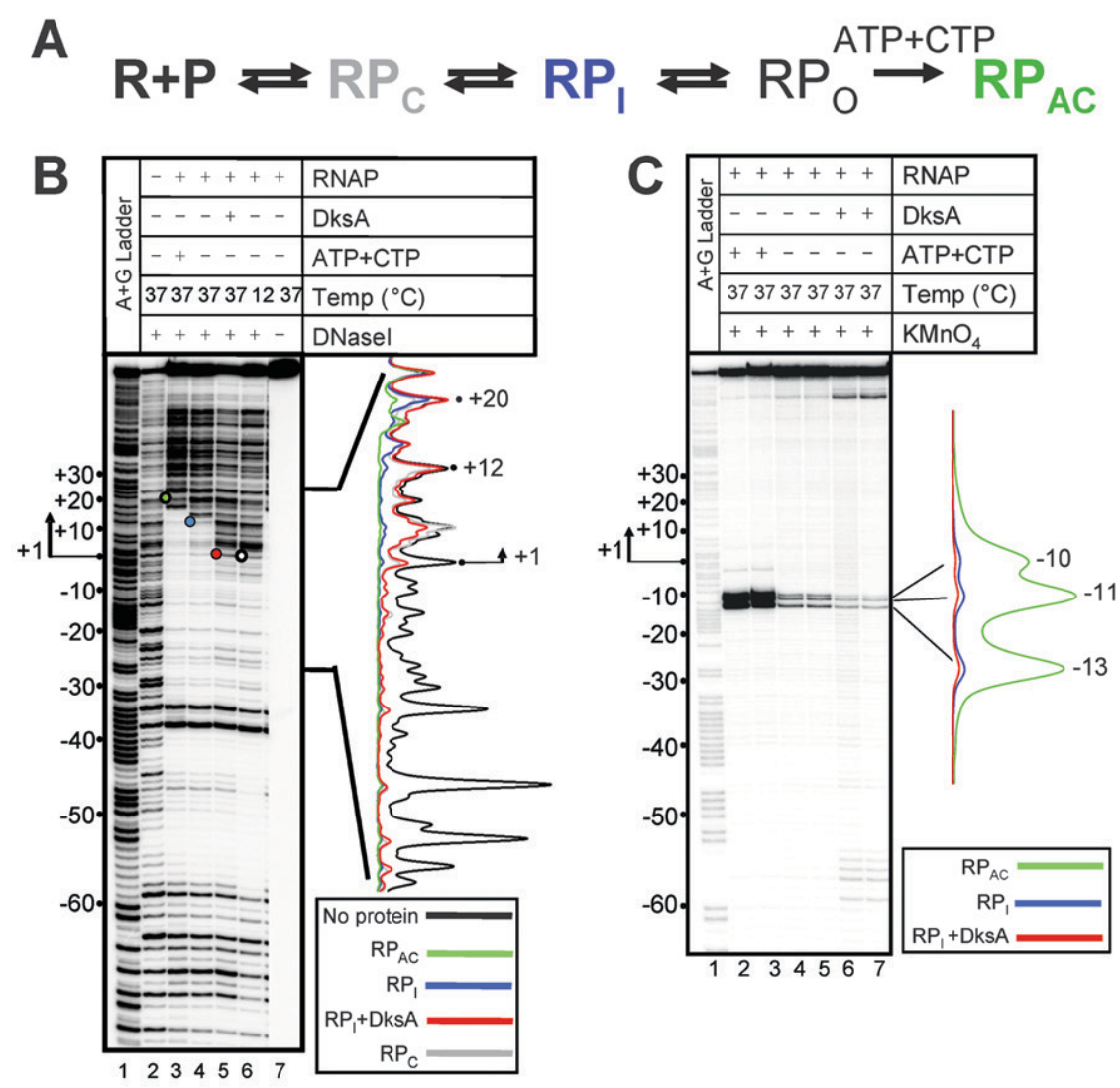

Figure 1. DksA shifts $\mathrm{RP}_{\mathrm{I}}$ at $r r n B \mathrm{P} 1$ to $\mathrm{RP}_{\mathrm{C}}$. (A) Kinetic steps in transcription initiation at $\operatorname{rrnB} \mathrm{P} 1$. (R) RNAP; (P) promoter; $\left(\mathrm{RP}_{\mathrm{C}}\right)$ closed complex; $\left(\mathrm{RP}_{\mathrm{I}}\right)$ intermediate complex; $\left(\mathrm{RP}_{\mathrm{O}}\right)$ open complex (transiently occupied at $\operatorname{rrnB} \mathrm{P} 1) ;\left(\mathrm{RP}_{\mathrm{AC}}\right)$ complex formed with ATP and CTP. $(B, D, E)$ DNaseI of $r r n B$ P1-RNAP complexes. Colored dots indicate the last downstream position protected by RNAP, and the corresponding gel traces to the right of the gel image indicate the overall extent of protection. (B) DNaseI footprints of $\mathrm{RP}_{\mathrm{C}}$ (lane 6), $\mathrm{RP}_{\mathrm{I}}$ (lane 4), and $\mathrm{RP}_{\mathrm{AC}}$ (lane 3). (Lane 5) DksA shifts $\mathrm{RP}_{\mathrm{I}}$ from a downstream endpoint of +12 to +1 . The template strand was ${ }^{32} \mathrm{P}$-labeled at the $3^{\prime}$ (upstream) end. $(C)$ Representative $\mathrm{KMnO}_{4}$ footprint of $\mathrm{rrnB}$ P1. Positions $-10,-11$, and -13 on the template strand are reactive in $\mathrm{RP}_{\mathrm{AC}}$ (lanes 1,2 , green trace at right of gel image) but are predominately unreactive in $\mathrm{RP}_{\mathrm{I}} \pm$ DksA (lanes 3-6, blue and red traces), and therefore $\mathrm{RP}_{\mathrm{I}}$ is closed. $(D)$ DksA does not affect the DNaseI footprint of $\mathrm{RP}_{\mathrm{C}}$ (complex formed at $12^{\circ} \mathrm{C}$ in the absence of competitor). (Lanes 3,4) Circle shows the downstream endpoint of protection in the $\mathrm{RP}_{\mathrm{C}}$ and $\mathrm{RP}_{\mathrm{C}}$ plus DksA footprints (see also red and gray traces at right). (E) DksA does not affect the DNaseI footprint of $\mathrm{RP}_{\mathrm{AC}}$ (complex formed at $37^{\circ} \mathrm{C}$ with ATP and CTP). (Lanes 3,4) Green dot shows the endpoint of downstream protection in $\mathrm{RP}_{\mathrm{AC}}$ (see also red and green traces at right). In $B, D$, and $E$, arrows mark the transcription start site, +1 , and positions $+1,+12$, and +20 are indicated on the traces for reference. The A + G ladders are sequence markers. RNAP was $40 \mathrm{nM}$, and DksA was $3.5 \mu \mathrm{M}$ in $B-D$. RNAP was $30 \mathrm{nM}$, and DksA was $1.5 \mu \mathrm{M}$ in $E$. The details are in the Materials and Methods and the Supplemental Material.

In contrast to the situation at most promoters, $\mathrm{RP}_{\mathrm{O}}$ is very short-lived at rRNA promoters (Barker et al. 2001a). DNA sequences in the core rRNA promoter are responsible for the short-lived nature of this complex, including a suboptimal contact between $\sigma$ region 1.2 and the discriminator, the region between the -10 hexamer and the transcription start site (Haugen et al. 2006). DksA and its cofactor ppGpp further shift the promoter-RNAP 
equilibrium in the dissociation direction, thereby inhibiting rRNA transcription (Barker et al. 2001a; Paul et al. 2004; Haugen et al. 2008). At promoters that form longlived complexes but bind RNAP very slowly, DksA/ppGpp can regulate transcription initiation positively (Paul et al. 2005). These increases result from a combination of direct and indirect effects of DksA/ppGpp on transcription (Zhou and Jin 1998; Barker et al. 2001a,b; Paul et al. 2005). Thus, the specific effect of DksA/ppGpp depends on the intrinsic kinetic characteristics of the promoter.

Some insights into the role of ppGpp were obtained from the identification of substitutions in the subunits of RNAP that suppressed growth defects of strains lacking relA and spoT, the genes responsible for ppGpp synthesis (Bartlett et al. 1998; Barker et al. 2001b; Trautinger and Lloyd 2002; Murphy and Cashel 2003; Szalewska-Palasz et al. 2007). Numerous substitutions were located in the proposed DNA path in transcription elongation complexes and destabilized RNAP-promoter complexes (Barker et al. 2001b; Trautinger and Lloyd 2002), consistent with the model that ppGpp functions in this manner.

To understand the mechanism of DksA action, we examined its effects on occupancy of complexes formed by RNAP at an rRNA promoter, $\operatorname{rrnB} \mathrm{P} 1$. The results indicated that DksA hinders conformational changes in RNAP and DNA during the transition from $\mathrm{RP}_{\mathrm{C}}$ to $\mathrm{RP}_{\mathrm{I}}$. Identification of amino acid substitutions in RNAP that mimicked or altered the effect of DksA allowed construction and initial confirmation of a working model for the action of DksA on transcription initiation.

\section{Results}

\section{DksA reduces occupancy of an $\mathrm{rrnB} P 1$ transcription} initiation intermediate

To understand the mechanism of rRNA transcription inhibition by DksA, we examined its effect on footprints of the $\operatorname{rrn} B \mathrm{P} 1$ promoter complex under different solution conditions in vitro. Manipulation of solution conditions has been used previously to examine intermediates by footprinting (e.g., Spassky et al. 1985; Cowing et al. 1989).

We previously identified three $\operatorname{rrn} B$ P1 promoter complexes- $\mathrm{RP}_{\mathrm{C}}, \mathrm{RP}_{\mathrm{I}}$, and $\mathrm{RP}_{\mathrm{AC}}$ (Fig. 1A; see below; Newlands et al. 1991; Bokal. et al. 1995; Bartlett et al. 1998). These complexes exhibit the same upstream endpoint in DNAseI footprints (approximately -60) but different extents of downstream protection from DNaseI (Fig. 1B), DNA strand opening (Figs. 1C; Supplemental Fig. S1), and resistance to displacement by competitors like heparin (for review, see Haugen et al. 2008).

The complex formed at $12^{\circ} \mathrm{C}$ is closed (as judged by the absence of DNA reactivity to $\mathrm{KMnO}_{4}$ ) (Supplemental Fig. S1), and downstream protection extends to approximately +1 (Fig. 1B, lane 6, white dot), similar to $\mathrm{RP}_{\mathrm{C}}$ at other promoters (Cowing et al. 1989; Schickor et al. 1990; Haugen et al. 2008). Because DNaseI requires access to at least 6 bp $3^{\prime}$ to the site of cleavage (Suck and Oefner 1986), the actual downstream boundary of $\mathrm{RP}_{\mathrm{C}}$ likely extends only to approximately -6 .
The complex formed at $37^{\circ} \mathrm{C}$ is also closed (Fig. 1C, cf. lanes 4,5 and lanes $2,3, \mathrm{RP}_{\mathrm{AC}}$, which is open [see below]), but DNA protection from DNaseI extends to approximately $+12\left(\mathrm{RP}_{\mathrm{I}}\right)$ (Fig. 1B, lane 4, blue dot), indicating an actual downstream boundary of approximately +6 . Most promoters form a stable $\mathrm{RP}_{\mathrm{O}}$ under these conditions (Haugen et al. 2008), but at $\operatorname{rrnB} \mathrm{P} 1, \mathrm{RP}_{\mathrm{O}}$ is unstable and represents only a minor fraction of the population at equilibrium (Fig. 1C, lanes 4,5 vs. lanes 2,3). $\mathrm{RP}_{\mathrm{I}}$ likely forms transiently at other promoters but is not observed in footprints because $\mathrm{RP}_{\mathrm{O}}$ is the predominant complex.

A competitor-stable complex at $\operatorname{rrnB} \mathrm{P} 1$ can be trapped at $37^{\circ} \mathrm{C}$ by addition of ATP and CTP, the first two nucleotides in the transcript (Gourse 1988; Newlands et al. 1991; Borukhov et al. 1993). This complex, $\mathrm{RP}_{\mathrm{AC}}$, is open as judged by its reactivity to $\mathrm{KMnO}_{4}$ (Fig. $1 \mathrm{C}$, lanes 2,3 ), and protection from DNaseI extends downstream to approimately +20 (Fig. 1B, lane 3, green dot), similar to the downstream endpoint observed in $\mathrm{RP}_{\mathrm{O}}$ at other promoters (for review, see Haugen et al. 2008).

We examined the effect of DksA on complexes formed by $\operatorname{rrn} B \mathrm{P} 1$. DksA shifted the downstream endpoint of DNaseI protection observed at $37^{\circ} \mathrm{C}$ in the absence of ATP and CTP from approximately +12 to approximately +1 (Fig. 1B, lane 5, red dot, cf. blue dot in lane 4, absence of DksA). DksA also reduced the minimal level of reactivity to $\mathrm{KMnO}_{4}$ observed at $37^{\circ} \mathrm{C}$ (Fig. 1C, lanes 6,7; cf. lanes 4,5 , absence of DksA). These results suggest that DksA destabilizes $\mathrm{RP}_{\mathrm{I}}$ at $\operatorname{rrn} B \mathrm{P} 1$ directly or indirectly by reducing promoter contacts with RNAP between approximately -6 and +6 , changing the predominant complex occupied at $37^{\circ} \mathrm{C}$ to one similar or identical to $\mathrm{RP}_{\mathrm{C}}$. The correlation between effects of DksA on $\mathrm{RP}_{\mathrm{I}}$ occupancy, promoter complex lifetime, and transcription is consistent with the model that DksA exerts its effects on $\operatorname{rrn} B$ $\mathrm{P} 1$ by shifting occupancy from $\mathrm{RP}_{\mathrm{I}}$ to $\mathrm{RP}_{\mathrm{C}}$.

These results also suggested that DksA does not destabilize $\mathrm{RP}_{\mathrm{C}}$, since the complex with the +1 downstream endpoint accumulated at $37^{\circ} \mathrm{C}$ in the presence of DksA. Consistent with this interpretation, DksA did not affect the DNaseI footprint of the complex formed by $\operatorname{rrnB} \mathrm{P} 1$ at $12^{\circ} \mathrm{C}$ (Fig. 1D, cf. normalized extent of downstream protection of lanes 3 and 4 in scan at right, indicated by white dot in gel image). If DksA had destabilized $\mathrm{RP}_{\mathrm{C}}$, a complete loss of protection by RNAP would have been observed, since the RNAP-promoter complex would have dissociated into its free components. DksA also had no effect on the footprints of $\mathrm{RP}_{\mathrm{AC}}$ at $r r n B \mathrm{P} 1$ (Fig. 1E, cf. lanes 3 and 4, extent of downstream protection indicated by green dot) or at two promoters where $\mathrm{RP}_{\mathrm{O}}$ is occupied at equilibrium, argI and lacUV5 (Supplemental Fig. S2). A shift in equilibrium occupancy of these open complexes to earlier transcription initiation intermediates by DksA would have resulted in a loss in protection from DNaseI between approximately +1 and approximately +20 .

We also examined effects of ppGpp on $\mathrm{RP}_{\mathrm{I}}$ (data not shown). ppGpp alone had little or no effect on the $\mathrm{RP}_{\mathrm{I}}$ footprint, consistent with its relatively small effect on transcription in vitro in the absence of DksA. ppGpp also exerted little or no additional effect on the footprint in 
the presence of DksA, consistent with its lack of additional effects on transcription when DksA concentrations are high (Paul et al. 2004).

\section{Selection and identification of $\Delta d k s A$ suppressor mutations in rpoBC}

In addition to inhibiting some promoters, DksA activates others (in conjunction with ppGpp), including some that direct transcription of genes for biosynthesis and transport of amino acids (Paul et al. 2005). We proposed previously that DksA might reduce the free energy of negatively and positively regulated promoter complexes similarly, but that transcriptional output might differ, depending on the intrinsic kinetic properties of individual promoters (i.e., affinity for RNAP, stability of $\mathrm{RP}_{\mathrm{O}}$, etc.) (Paul et al. 2005). Therefore, we reasoned that identification of mutations affecting either activation or inhibition by DksA might provide insight into the mechanisms of both processes.

We identified residues in RNAP important for DksA function by selecting for suppressor mutations that allowed strains lacking $d k s A$ to form colonies within $2 \mathrm{~d}$ at $30^{\circ} \mathrm{C}$ on a medium lacking amino acids. Spontaneous suppressors appeared at a frequency of $\sim 10^{-4}$ to $10^{-5}$, possibly by bypassing the $d k s A$ requirement for amino acid biosynthesis or transport (see Discussion; Paul et al. 2005). Sixty-seven mutants ( $\Delta d k s A$ suppressors) were analyzed.

Like strains lacking $d k s A$, strains without relA and spoT are unable to plate on minimal medium lacking amino acids. Spontaneous $\Delta r e l A \Delta s p o T$ suppressors map in $r p o B$ and rpoC (Bartlett et al. 1998; Barker et al. 2001b; Trautinger and Lloyd 2002; Murphy and Cashel 2003; Szalewska-Palasz et al. 2007), and (at a much lower frequency) in rpoD (Hernandez and Cashel 1995). Therefore, we measured linkage to $r p o B C$ as a first step in mapping the $\Delta d k s A$ suppressor mutations. In each of the 67 suppressor strains, replacement of the $r p o B C$ region with wild-type $r p o B C$ by transduction with $\mathrm{P} 1$ vir resulted in loss of suppression (loss of growth on medium lacking amino acids). Furthermore, P1 transduction of $\Delta d k s A$ suppressors to a fresh $\Delta d k s A$ strain resulted in growth on minimal medium in all 16 cases where this was tested (Supplemental Material; Supplemental Table S2). Taken together, these results strongly suggested that the $\Delta d k s A$ suppressor mutations were in $r p o B C$.

The $r p o B$ and $r p o C$ genes were sequenced from 52 isolates (Table 1). After elimination of duplicates, 29 different mutations were identified, representing 24 single amino acid substitutions (two of which coded for different substitutions for the same amino acid), one double substitution, three deletions, and one insertion. Twenty mutations are in $r p o C$, eight are in $r p o B$, and the double contains a mutation in each gene. Figure 2 displays the positions of $\Delta d k s A$ suppressors superimposed on a model of $\mathrm{RP}_{\mathrm{O}}$ that was based on the X-ray structure of the Thermus aquaticus fork-junction complex (Murakami et al. 2002; Lawson et al. 2004). The positions of most of the $\Delta d k s A$ suppressors (21 out of 28) are clustered in, or very close to, the RNAP switch regions (Table 1).

The switch regions serve as a hinge at the base of the RNAP clamp and form a network of salt linkages to the bridge helix (BH) (Cramer et al. 2001; Gnatt et al. 2001; Vassylyev et al. 2007a). The switches may undergo conformational changes and/or folding transitions in the course of binding to DNA and have been proposed to coordinate clamp opening/closing during transcription initiation and elongation (Cramer et al. 2001; Gnatt et al. 2001; Mukhopadhyay et al. 2008). Switch region residues directly contact template strand DNA in models of $\mathrm{RP}_{\mathrm{O}}$ and in the TEC (Lawson et al. 2004; Vassylyev et al. 2007a; Belogurov et al. 2008), but because there is no structure of $\mathrm{RP}_{\mathrm{I}}$, the complex on which DksA acts (see above), it remains to be determined if promoter DNA has bent toward the active site sufficiently to contact the switch regions directly in this intermediate.

Of the seven positions not in, or directly adjacent to, the switch regions, two ( $\beta^{\prime}$ H450R and $\beta^{\prime}$ K650T) are likely near or in the DksA-binding site, and two others $\left(\beta^{\prime}\right.$ $\Delta 212-217$ and $\left.\beta^{\prime} \Delta 1185-1216\right)$ likely affect DNA interactions downstream from the position of the transcription initiation bubble. The other three positions are in the $\beta$ subunit (Y395D, R454H/R454L, and H551P), and their selection might also be rationalized by effects on the DNA path (e.g., $\beta$ H551P is in fork loop 2, between the separated strands of DNA and adjacent to the $\mathrm{BH}$ in $\mathrm{RP}_{\mathrm{O}}$ ) (Fig. 2; Lawson et al. 2004).

Eighteen of the suppressors are near the template strand in the model of $\mathrm{RP}_{\mathrm{O}}$ between positions approximately -2 and approximately +6 , and three are near the nontemplate strand between approximately -2 and approximately +6 , correlating with the region of DNA differentially protected in the footprints of $\mathrm{RP}_{\mathrm{C}}$ versus $\mathrm{RP}_{\mathrm{I}}$.

In contrast to the $\Delta d k s A$ suppressors, a large majority of which are in $\beta^{\prime}$, a majority of the $\Delta$ relA $\Delta$ spoT suppressors are in $\beta$. Furthermore, 22 of the $29 \Delta d k s A$ suppressors were not identified previously as suppressors of ArelAsspoT strains (Supplemental Table S3; Bartlett et al. 1998; Trautinger and Lloyd 2002; Murphy and Cashel 2003; Szalewska-Palasz et al. 2007). As noted previously (Trautinger and Lloyd 2002), many of the $\Delta$ relA $\Delta$ spoT suppressors are spread along the main channel of RNAP. Those that have been tested reduce the lifetimes of promoter complexes (Bartlett et al. 1998; Zhou and Jin 1998; Barker et al. 2001b; Trautinger et al. 2005; Szalewska-Palasz et al. 2007), supporting the model that ppGpp functions by reducing promoter complex lifetime (see Discussion for further comparison of the $\Delta d k s A$ and $\Delta r e l A \Delta s p o T$ suppressors).

In summary, we propose that switch region residues play a central role in DksA function, accounting for their identification in our selection. Furthermore, because $\mathrm{RP}_{\mathrm{I}}$ is the complex on which DksA funcitons, these data suggest that the switch regions might affect the $\mathrm{RP}_{\mathrm{C}}$-to- $R \mathrm{P}_{\mathrm{I}}$ transition by controlling clamp opening to allow DNA entry and/or by establishing contacts directly with promoter DNA at this step in the transcription initiation mechanism.

\section{$\Delta d k s A$ suppressors reduce $\operatorname{rrn} B$ P1 transcription}

To test whether the $r p o B C$ mutants mimic the effects of $d k s A$ in vivo and thus compensate for its absence, we measured effects of five $\Delta d k s A$ suppressors (including representatives in RNAP switch regions 1 [ $\beta^{\prime}$ F1325L], 2 
Rutherford et al.

Table 1. Substitutions in RNAP allowing growth of $\Delta$ dksA cells on minimal medium lacking amino acids

\begin{tabular}{|c|c|c|c|c|}
\hline Subunit $^{\mathrm{a}}$ & Substitution $^{\mathrm{b}}$ & Isolates $^{\mathrm{c}}$ & RNAP region $^{\mathrm{d}}$ & Previously reported $^{\mathrm{e}}$ \\
\hline \multicolumn{5}{|c|}{ Single amino acid substitutions } \\
\hline$\beta$ & Y395D & 1 & Lobe & $\mathrm{f}$ \\
\hline$\beta$ & $\mathrm{R} 454 \mathrm{H}$ & 7 & Protrusion (lobe/fork) & $\mathrm{g}, \mathrm{h}$ \\
\hline$\beta$ & R454L & 2 & Protrusion (lobe/fork) & $\mathrm{g}$ \\
\hline$\beta$ & H551P & 1 & Fork loop 2 & $\mathrm{f}, \mathrm{g}$ \\
\hline$\beta$ & Q1264P & 1 & Switch 3 & $\mathrm{~g}$ \\
\hline$\beta$ & G1267V & 1 & Switch 3 & \\
\hline$\beta$ & $\mathrm{R} 1269 \mathrm{H}$ & 1 & Switch 3 & \\
\hline$\beta$ & P1317L & 5 & Near $\omega, 4 \AA$ from switch 4 & \\
\hline$\beta^{\prime}$ & G333D & 1 & Switch 2 & \\
\hline$\beta^{\prime}$ & K334I & 1 & Switch 2 & \\
\hline$\beta^{\prime}$ & G336C & 1 & Switch 2 & \\
\hline$\beta^{\prime}$ & R337S & 5 & Switch 2 & \\
\hline$\beta^{\prime}$ & L343I & 1 & Switch 2 & \\
\hline$\beta^{\prime}$ & D348Y & 1 & Switch 2 & $\mathrm{~g}$ \\
\hline$\beta^{\prime}$ & H450R & 1 & Active site region & \\
\hline$\beta^{\prime}$ & K650T & 1 & Secondary channel rim & \\
\hline$\beta^{\prime}$ & R799L & 1 & Bridge helix, touching switch 1 & \\
\hline$\beta^{\prime}$ & Q805P & 1 & Bridge helix, $5 \AA$ from switch 1 & \\
\hline$\beta^{\prime}$ & G1308C & 1 & Switch 1 & \\
\hline$\beta^{\prime}$ & L1314Q & 1 & Switch 1 & \\
\hline$\beta^{\prime}$ & S1324L & 3 & Switch 1 & \\
\hline$\beta^{\prime}$ & F1325L & 3 & Switch 1 & \\
\hline$\beta^{\prime}$ & F1325V & 1 & Switch 1 & \\
\hline$\beta^{\prime}$ & G1354C & 1 & Near $\omega, 6 \AA$ from switches 4,5 & \\
\hline \multicolumn{5}{|c|}{ Double amino acid substitutions } \\
\hline$\beta / \beta^{\prime}$ & R1246C/K334Q & 1 & Switch $3 /$ switch2 & \\
\hline \multicolumn{5}{|c|}{ Insertions and deletions } \\
\hline$\beta^{\prime}$ & $\Delta 212-217$ & 1 & Inside clamp head & $h, i$ \\
\hline$\beta^{\prime}$ & $\Omega 320-324^{j}$ & 1 & Rudder, $7 \AA$ from switch 2 & \\
\hline$\beta^{\prime}$ & $\Delta 1185-1216$ & 2 & Cleft region & \\
\hline$\beta^{\prime}$ & $\Delta 1335-1337$ & 1 & Inside clamp core, touching switch 1 & \\
\hline
\end{tabular}

${ }^{a}$ rpoB encodes $\beta ;$ rpoC encodes $\beta^{\prime}$.

${ }^{\mathrm{b}}$ Amino acid substitution (original amino acid followed by the residue number and the new amino acid).

${ }^{\mathrm{c}}$ Number of isolates.

${ }^{\mathrm{d}}$ Location of substitution (as defined by structural alignment with yeast RNA pol II (Cramer et al. 2001).

${ }^{e}$ Previously isolated as suppressor of amino acid auxotrophy of $\Delta r e l A \Delta s p o T$ mutant.

${ }^{\mathrm{f}}$ Trautinger and Lloyd 2002.

${ }^{\mathrm{g}}$ Szalewska-Palasz et al. 2007.

${ }^{\text {h}}$ Bartlett et al. 1998.

${ }^{i}$ Murphy and Cashel 2003.

'Tandem duplication of $\beta$ ' residues 320-324.

[ $\beta^{\prime}$ R337S], and 3 [ $\beta$ G1267V; $\beta$ R1269H], and the $\mathrm{BH}\left[\beta^{\prime}\right.$ Q805P]) on expression of $\operatorname{rrn} B$ P1-lacZ fusions. Consistent with our previous observations (Paul et al. 2004), deletion of $d k s A$ in a strain wild-type for $r p o B C$ increased $\operatorname{rrn} B$ P1 activity approximately fourfold in $\log$ phase (Fig. $3 \mathrm{~A})$. In contrast, $\operatorname{rrn} B \mathrm{P} 1$ activity in $\triangle d k s A$ strains containing the suppressor mutations was similar to that in the strain with wild-type $d k s A$ and wild-type rpoBC (Fig. $3 \mathrm{~A})$. Thus, the $r p o B C$ mutations mimicked the effect of wild-type $d k s A$ on $r r n B P 1$ in vivo, without inhibiting the activities of two control promoters, lacUV5 and $\arg I$ (Supplemental Fig. S3).

To determine if the effects of the suppressor mutations on rRNA promoter activity were direct, we measured transcription in vitro by eight of the mutant RNAPs (including the five tested in vivo). Seven of the purified
RNAPs contained substitutions in or near the switch regions or $\mathrm{BH}$, and one contained a substitution near the position of $\omega$ (which has been implicated in ppGpp function) (Vrentas et al. 2005). In each case, transcription from $r r n B$ P1 was much lower than transcription by wild-type RNAP, whereas transcription from a control promoter, RNA1, was relatively unaffected by the RNAP substitutions. Transcription from $r r n B$ P1 by the mutant RNAPs was even lower than by wild-type RNAP in the presence of DksA and ppGpp (Fig. 3B). Thus, effects of the rpoBC mutations on $r r n B P 1$ are promoter-specific and direct.

$\Delta d k s A$ suppressors shift the $R P_{C} \leftrightarrow R P_{I}$ equilibrium in the dissociation direction

DksA reduces the lifetimes of complexes formed at all promoters that have been examined, shifting the equilibrium 

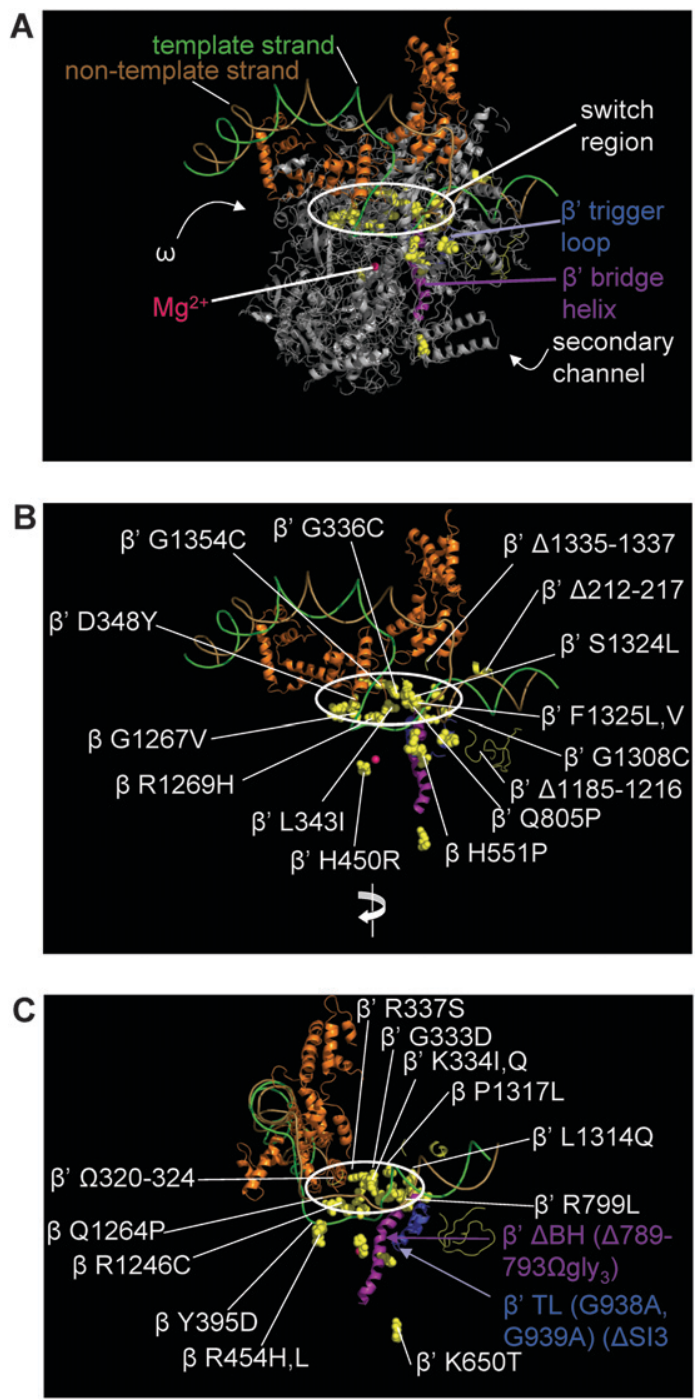

Figure 2. Substitutions that suppress the effects of the $\Delta d k s A$ mutation cluster in the switch and $\mathrm{BH}$ regions of RNAP near the transcription start site. (A) Model of $\mathrm{RP}_{\mathrm{O}}$ based on the $\mathrm{T}$. aquaticus fork-junction complex (Murakami et al. 2002; Lawson et al. 2004). In this view, upstream DNA enters the enzyme at the top left, and downstream DNA exits the main channel to the right. $\beta, \beta^{\prime}, \omega$, and $\alpha_{2}$ are gray; $\sigma$ is orange; template strand is green; nontemplate strand is brown; active site $\mathrm{Mg}^{2+}(\mathrm{Mg} 1)$ is a magenta sphere; $\beta^{\prime} \mathrm{BH}$ is purple; and $\beta^{\prime} \mathrm{TL}$ is light blue (TL is more visible in $C$ ). Arrows point to $\omega$ (on back face) and the secondary channel (underside). Positions of substitutions that allow $\Delta d k s A$ mutants to grow in the absence of amino acids are in yellow spacefill. Positions of deletions are also indicated in yellow. The oval shows the approximate boundary of the switch regions. In $B$, the orientation is the same as in $A$, but $\beta, \beta^{\prime}, \omega$, and $\alpha_{2}$ have been omitted, except for the residues in yellow $(\Delta d k s A$ suppressors), the $\mathrm{BH}$, and TL. In $C$, RNAP is rotated $90^{\circ}$. Deletions and insertions are indicated by $\Delta$ and $\Omega$, respectively. Approximate positions of site-directed mutants in the $\mathrm{BH}$ and $\mathrm{TL}$, discussed later in the text, are also indicated.

in the dissociation direction and inhibiting transcription from promoters that form intrinsically short-lived complexes (Paul et al. 2004; Rutherford et al. 2007; Haugen et al. 2008). To determine whether the $\Delta d k s A$ suppressors in $r p o B C$ altered the lifetimes of promoter complexes, we tested the effects of seven mutant RNAPs on complexes formed by the lacUV5 and argI promoters (Barker et al. 2001b; Paul et al. 2005). (The decay rates of $\operatorname{rrnB}$ P1 complexes with the mutant RNAPs were too fast for us to measure them accurately [data not shown].) The mutant RNAPs formed complexes with the lacUV5 and argI promoters that were as much as 50 -fold shorter-lived than the complexes formed by wild-type RNAP (Fig. 3C,D and legend). Complexes made by the mutant RNAPs in the absence of DksA and ppGpp had lifetimes similar to those made by wild-type RNAP in the presence of DksA and ppGpp.

We also performed DNaseI footprints on $\operatorname{rrn} B$ P1 with four mutant RNAPs in the absence of DksA to determine whether the protection pattern was the same as with wildtype RNAP in the presence of DksA. Under conditions in which wild-type RNAP without DksA formed a complex that extended to approximately $+12\left(\mathrm{RP}_{\mathrm{I}}\right)$, and wild-type RNAP with DksA made a complex that extended to approximately +1 (Fig. 3E, lanes 4,5 ), the mutant RNAPs ( $\beta^{\prime}$ G333D) (Fig. 3E, lane 6; $\beta^{\prime}$ R337S, $\beta^{\prime}$ F1325V, and $\beta^{\prime}$ G1354C; data not shown) made complexes that extended only to approximately +1 . We conclude from both the lifetime and footprint assays that the suppressor substitutions mimic the effect of DksA on wild-type RNAP by altering interactions between RNAP and the promoter, shifting the $\mathrm{RP}_{\mathrm{C}} \leftrightarrow \mathrm{RP}_{\mathrm{I}}$ equilibrium toward dissociation, and that the switch regions and $\mathrm{BH}$ play an essential role in this step in transcription initiation.

\section{Role of the trigger loop (TL) in DksA signal transmission}

We propose that DksA ultimately targets interactions between RNAP and promoter DNA either by targeting residues that affect the clamp conformation during $R P_{I}$ formation or that directly contact $\mathrm{DNA}$ in $\mathrm{RP}_{\mathrm{I}}$. In either case, these RNAP residues in the switch regions are 25-40 $\AA$ away from where DksA binds in the secondary channel. Thus, signals must be propagated allosterically. Since sections of both the TL and the $\sim 60$ - $\AA$-long BH likely are accessible to DksA in the secondary channel (Vassylyev et al. 2002, 2007a), they are candidates for transmitting the conformational changes.

The TL is located at the bottom of the secondary channel, assumes multiple conformations during nucleotide addition (Vassylyev et al. 2007b), and is positioned to interact with the $\mathrm{BH}$ (see below). To address the role of the TL in DksA function, we examined effects of DksA on two previously constructed mutant RNAPs (Toulokhonov et al. 2007). In both constructs, $\beta^{\prime}$ contains an alteration in the TL and lacks sequence insertion 3 (SI3; residues 943-1130), a region of $\beta^{\prime}$ that interrupts the TL in Escherichia coli but not in Thermus RNAP (Vassylyev et al. 2007b). In one mutant, $\beta^{\prime} \Delta \mathrm{TL}(\Delta \mathrm{SI} 3)$, the TL and SI3 ( $\beta^{\prime}$ residues 931-1137) are replaced by three alanine residues. In the other, $\beta^{\prime}$ TL GG $\rightarrow \mathrm{AA}(\Delta \mathrm{SI} 3)$, SI3 is deleted, and the TL contains two alanine substitutions (G938A and G939A) that result in an altered TL conformation 
Figure 3. $\Delta d k s A$ suppressors mimic the effect of DksA on $\operatorname{rrnB}$ P1 transcription. (A) rrnB P1 promoter activities in $\Delta d k s A$ strains containing wild-type or mutant $r p o B / r p o C$ alleles. $\beta$-Galactosidase activities from $\operatorname{rrnB}$ P1-lacZ fusions (three or more replicate cultures). (B) Transcription from $\operatorname{rrn} B$ P1 by $\Delta d k s A$ suppressor RNAPs in vitro. Relative transcription (wild-type RNAP $=100 \%$ ) is indicated \pm ppGpp/DksA (average of duplicate lanes; see the Materials and Methods and the Supplemental Material). $(C, D)$ Lifetimes of promoter complexes formed by $\Delta d k s A$ suppressor RNAPs. The half-lives in $C$ were measured using a filter binding assay and in $D$ using in vitro transcription as a readout, as described in the Materials and Methods and the Supplemental Material. Plots show the fraction of complexes remaining /or transcription) as a function of time after heparin addition for the lacUV5 $(C)$ and $\operatorname{argI}(D)$ promoter. Absolute half-life (min) and error values in $C$, the lacUV5 complex, were wild-type RNAP, $106 \pm 20$; wild-type RNAP with DksA, $38 \pm 7.1$; wild-type RNAP with DksA and ppGpp, $5.6 \pm 1.2$. For clarity, an average regression line is provided for the eight $\Delta d k s A$ suppressor mutant RNAPs listed in $B$; the absolute half-life values ranged from $3.4 \pm 0.3$ to $6.2 \pm 0.8$. Absolute half-lives for $D$, the $\operatorname{argI~complex,~are~in~Figure~5C.~}(E)$ DNaseI footprints at $37^{\circ} \mathrm{C}$ of a representative $\Delta d k s A$ suppressor RNAP, $\beta^{\prime}$ G333D, on $r r n B$ P1. The conditions are indicated above each lane and in the Materials and Methods. Open circles indicate the extent of downstream protection with wild-type RNAP (lane 4, thick line in scan at right), with wild-type RNAP + DksA(lane 5, dashed line in scan), and with mutant RNAP (lane 6, dotted line in scan). Note the absence of protection in the region from +1 to approximately +12 with the mutant RNAP. Footprints with the $\beta^{\prime}$ R337S, $\beta^{\prime}$ F1325L, and $\beta^{\prime}$ G1354C RNAPs were similar to that with $\beta^{\prime}$ G333D RNAP. DksA was $2 \mu \mathrm{M}$, and ppGpp was $100 \mu \mathrm{M}$.

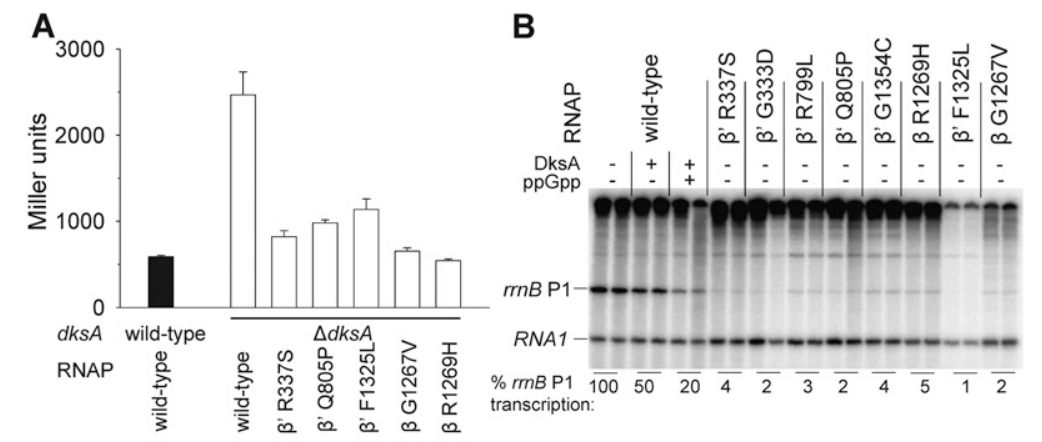

C
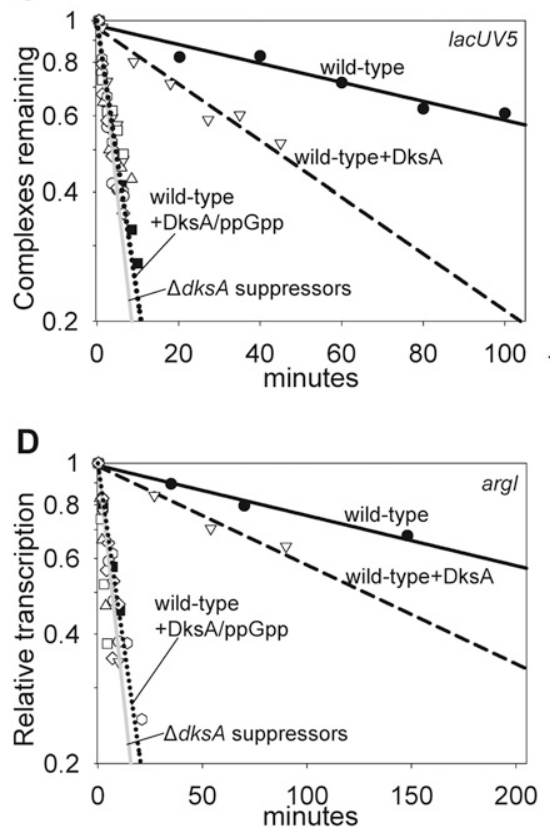

E

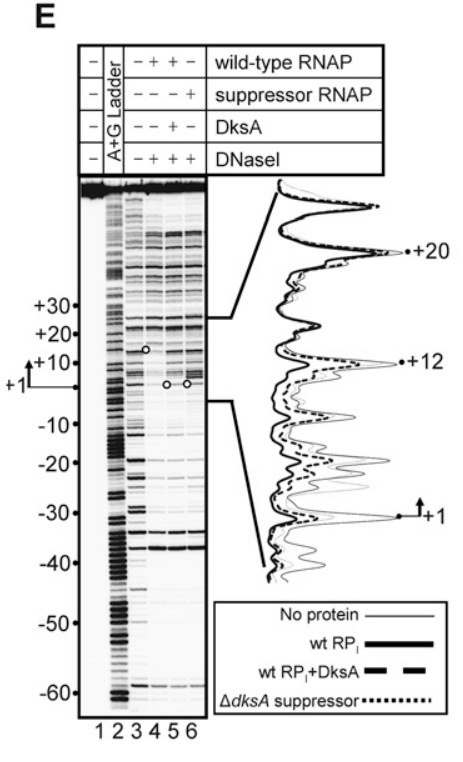

00 and a dramatic decrease in the rate of NTP addition during transcription elongation (Vassylyev et al. 2007b).

We compared the lifetimes of promoter complexes formed by $\beta^{\prime} \Delta \mathrm{TL}(\Delta \mathrm{SI} 3), \beta^{\prime} \mathrm{TL}$ GG $\rightarrow \mathrm{AA}(\Delta \mathrm{SI} 3), \beta^{\prime} \Delta \mathrm{SI} 3$, or wild-type RNAP in the absence and presence of DksA (Fig. 4). Whereas DksA decreased the lifetimes of the wild-type, $\beta^{\prime} \Delta \mathrm{SI} 3$, and $\beta^{\prime} \mathrm{TL}$ GG $\rightarrow \mathrm{AA}(\Delta \mathrm{SI} 3)$ RNAPs fivefold to ninefold (Fig. 4A-C), DksA had little or no effect on the $\beta^{\prime} \Delta \mathrm{TL}(\Delta \mathrm{SI})$ ) RNAP (Fig. 4D), suggesting that the TL is needed for DksA to bind RNAP and/or perform a subsequent step in DksA function. The slightly shorterlived complex that the $\beta^{\prime} \Delta \mathrm{TL}(\Delta \mathrm{SI} 3)$ RNAP forms with the promoter (approximately threefold compared with the $\beta^{\prime} \Delta$ SI3 RNAP, which is DksA-responsive) is insufficient to account for the absence of an effect of DksA, since RNAP mutants that decrease the relative lifetime of promoter complexes far more than the $\beta^{\prime} \Delta \mathrm{TL}(\Delta \mathrm{SI} 3)$ RNAP still respond to DksA (Fig. 5C; data not shown). To address whether DksA binds to $\beta^{\prime} \Delta \mathrm{TL}(\Delta \mathrm{SI} 3)$ RNAP, we used an assay in which hydroxyl radicals are generated at the RNAP active center by replacement of $\mathrm{Mg}^{2+}$ with
$\mathrm{Fe}^{2+}$, which results in cleavage of the coiled-coil tip of DksA (Perederina et al. 2004). DksA was cleaved similarly by the $\beta^{\prime} \Delta \mathrm{TL}(\Delta \mathrm{SI} 3)$ RNAP and the wild-type RNAP, indicating it bound to both RNAPs (Fig. 4E). These results suggest that an interaction of DksA with the TL may be required to generate the allosteric signal transmitted from the secondary channel to RNAP residues that interact with DNA.

The complexes formed by the $\beta^{\prime}$ TL GG $\rightarrow \mathrm{AA}(\Delta \mathrm{SI} 3)$ and $\beta^{\prime} \Delta$ SI3 RNAPs were threefold to fourfold shorterlived than the wild-type RNAP complexes (Fig. 4A-C). To determine whether these mutant RNAPs were more sensitive to DksA than the wild-type RNAP, the DksA concentration dependencies of the promoter complex lifetimes were compared. $\beta^{\prime}$ TL GG $\rightarrow$ AA $(\Delta$ SI3) RNAP required $\sim 0.1 \mu \mathrm{M}$ DksA for half-maximal reduction of complex lifetime, whereas $\beta^{\prime} \Delta$ SI3 RNAP and wild-type RNAP required $\sim 0.3-0.4 \mu M$ DksA (Fig. 4F). These results suggest that the $\beta^{\prime}$ G938A and G939A TL substitutions (and not the SI3 deletion) favor a TL conformation that facilitates transmission of the DksA-binding signal to its site of action. 
A

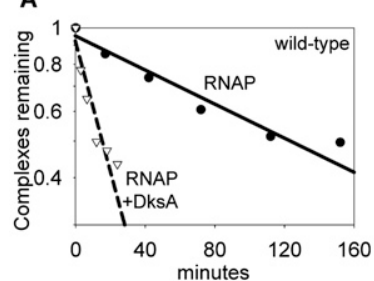

C

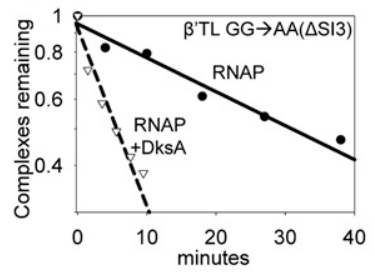

E

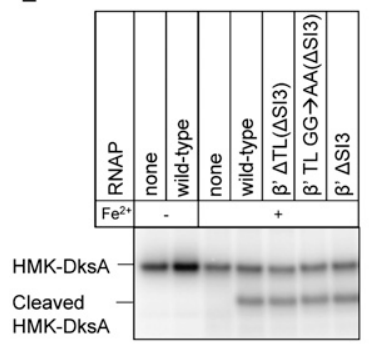

B

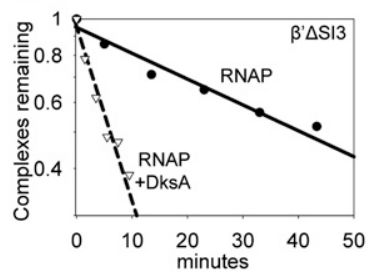

D

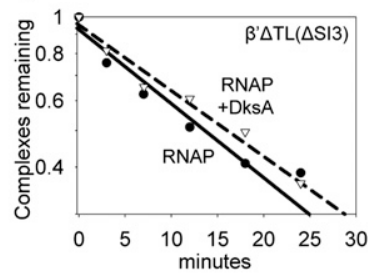

$\mathbf{F}_{10}$

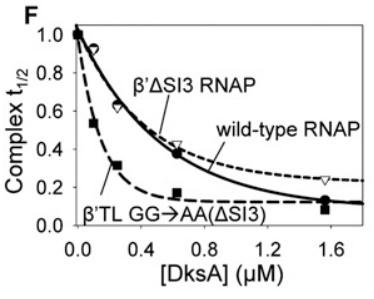

Figure 4. Effects of TL mutants on DksA function. $(A-D)$ Halflives of RNAP complexes containing the lacUV5 promoter were measured by filter retention. Plots show the fraction of complexes remaining as a function of time after heparin addition. The fold-decrease in the half-life of the complex resulting from addition of $1.6 \mu \mathrm{M}$ DksA is in parentheses: $(A)$ wild-type RNAP $(8.1 \pm 2.4),(B) \beta^{\prime} \Delta$ SI3 RNAP $(5.3 \pm 1.3), \beta^{\prime}$ TL GG $\rightarrow$ AA( $(\Delta \mathrm{SI} 3)$ RNAP $(8.6 \pm 3.7), \beta^{\prime} \Delta \mathrm{TL}(\Delta \mathrm{SI} 3)$ RNAP $(0.93 \pm 0.04)$. (E) $\mathrm{Fe}^{2+}$ cleavage assay for DksA binding to wild-type and mutant RNAPs. $(F)$ The concentration dependence of effects of DksA on the lifetimes of lacUV5 promoter complexes were measured with wild-type or mutant RNAPs. See the Supplemental Material for further information.

\section{Role of the BH in DksA signal transmission}

The $\mathrm{BH}$ is accessible through the secondary channel, and it interacts with the TL. Furthermore, the C-terminal region of the $\mathrm{BH}$ extends to the switch region and may contact promoter DNA near the transcription start site (Gnatt et al. 2001). Thus, the $\mathrm{BH}$ is a candidate for transmitting the signal initiated by DksA binding in the secondary channel. To address the role of the $\mathrm{BH}$, we tested effects of DksA on a mutant RNAP in which five amino acids near the center of the $\mathrm{BH}$ at the base of the secondary channel were replaced by a glycine linker $\left(\beta^{\prime}\right.$ $\Delta 789-793 \Omega$ gly3, referred to as $\beta^{\prime} \Delta \mathrm{BH}$ ) (see Fig. 2C; Toulokhonov et al. 2007). Even at the highest concentrations of DksA used, where effects on promoter complex lifetime were saturating for wild-type RNAP, DksA had much smaller effects on the $\beta^{\prime} \Delta B H$ RNAP than on wild-type RNAP (Fig. 5A). The dramatic effect of the $\Delta \mathrm{BH}$ mutation on the effect of DksA could not be explained by

an absence of DksA binding, since $\mathrm{Fe}^{2+}$-mediated cleavage of DksA was still observed with the mutant enzyme (Fig. 5B). We conclude that the $\mathrm{BH}$ contributes to the network of interactions that transmits effects of DksA binding to the promoter.

\section{A switch mutant resistant to the effect of DksA}

Effects of the $\Delta d k s A$ suppressors on the $\mathrm{RP}_{\mathrm{C}}$-to- $\mathrm{RP}_{\mathrm{I}}$ transition suggested that the switch region substitutions might perform the same function as DksA, either affecting clamp opening/closing or reducing direct RNAPpromoter contacts in $\mathrm{RP}_{\mathrm{I}}$. Furthermore, our data suggested that effects of DksA binding in the secondary channel might be transmitted to the switch regions via the $\mathrm{TL}$ and the $\mathrm{BH}$. We next addressed whether any of the positions in the switches identified by the $\Delta d k s A$

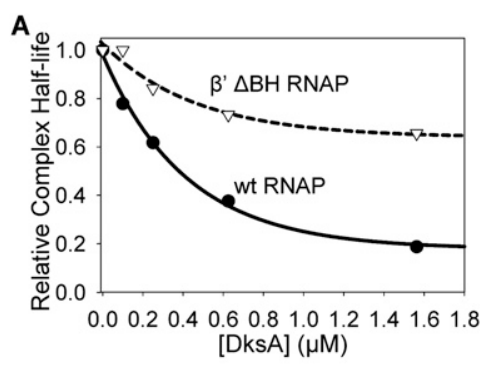

B

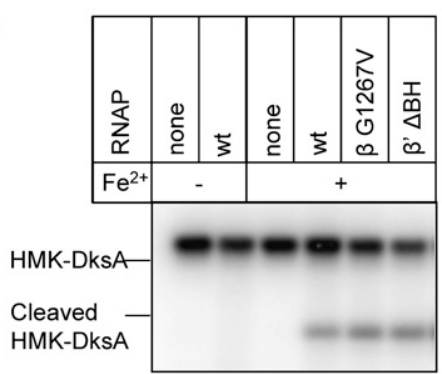

C

\begin{tabular}{lll}
\hline RNAP & $\mathrm{t} 1 / 2(\mathrm{~min})$ & $\mathrm{t} 1 / 2(+/-\mathrm{Dks})$ \\
\hline$w t$ & $239 \pm 22$ & $0.54 \pm 0.14$ \\
$\beta^{\prime}$ G333D & $5.98 \pm 1.1$ & $0.57 \pm 0.13$ \\
$\beta^{\prime}$ R337S & $22.0 \pm 10$ & $0.53 \pm 0.18$ \\
$\beta^{\prime}$ R799L & $8.5 \pm 2.1$ & $0.49 \pm 0.20$ \\
$\beta^{\prime}$ Q805P & $4.2 \pm 0.8$ & $0.49 \pm 0.05$ \\
$\beta^{\prime}$ F1325L & $8.0 \pm 1.2$ & $0.41 \pm 0.07$ \\
$\beta^{\prime}$ G1354C & $11.6 \pm 3.0$ & $0.38 \pm 0.09$ \\
$\beta$ G1267V & $8.5 \pm 3.2$ & $1.00 \pm 0.24$ \\
\hline
\end{tabular}

Figure 5. Mutant RNAPs defective in the response to DksA. (A) Substitutions in the $\mathrm{BH}$ decrease the effect of DksA on promoter complex lifetime. The concentration dependence of effects of DksA on the lifetimes of lacUV5 promoter complexes were measured with wild-type or $\triangle \mathrm{BH}$ RNAP. See the Supplemental Material for further information. $(B)$ DksA binding was measured by $\mathrm{Fe}^{2+}$ - mediated cleavage (see the Materials and Methods and the Supplemental Material) for wild-type, $\beta^{\prime} \Delta \mathrm{BH}$, and $\beta$ G1267V RNAPs. (C) Half-lives of complexes containing wild-type or mutant RNAPs on the $\operatorname{argI}$ promoter (see the Materials and Methods). For each RNAP, the value in column 2 is the absolute half-life, and the value in column 3 is the ratio of the half-life $\pm 2.25 \mu \mathrm{M}$ DksA. 
suppressor mutations were resistant to DksA function and therefore, like the TL and $\mathrm{BH}$, might be on the signal transduction pathway. We tested the effects of DksA on the complexes formed by seven $\Delta d k s A$ suppressor RNAPs. Each of the mutant RNAPs made promoter complexes with short half-lives. However, DksA further reduced the lifetimes of the complexes formed by six of the seven mutants, indicating that these residues are not essential for DksA function (Fig. 5C).

$\beta$ G1267V RNAP (a substitution in switch region 3) was unaffected by DksA (Fig. 5C). DksA was cleaved by $\mathrm{Fe}^{2+}$ in the active site of the mutant RNAP (Fig. 5B), suggesting that the defect occurred subsequent to DksA binding. Although further studies will be needed to rule out quantitative differences in binding at low DksA concentrations, we conclude that $\beta$ G1267 might play a direct role in the network of promoter-RNAP interactions targeted by DksA (see Discussion).

\section{Discussion}

Promoter-RNAP interactions in $R P_{C}$ and $R P_{I}$

The unusual kinetic properties of $\operatorname{rrnB} \mathrm{P} 1$ made it possible to study effects of DksA on occupancy of three different complexes: two closed complexes, $\mathrm{RP}_{\mathrm{C}}$ (highly occupied at $12^{\circ} \mathrm{C}$ ) and $\mathrm{RP}_{\mathrm{I}}$ (highly occupied at $37^{\circ} \mathrm{C}$ ); and an open complex, $\mathrm{RP}_{\mathrm{AC}}$ (stabilized by the addition of the first two NTPs in the transcript). As with the closed complex formed at low temperatures at other promoters (e.g., Cowing et al. 1989; Schickor et al. 1990), $\mathrm{RP}_{\mathrm{C}}$ is characterized by a shortened DNaseI downstream footprint (to +1 ), relative to that in $\mathrm{RP}_{\mathrm{AC}}$ at $r r n B \mathrm{P} 1$ (to +20$)$ and in $\mathrm{RP}_{\mathrm{O}}$ at other promoters. This indicates that promoter DNA in $\mathrm{RP}_{\mathrm{C}}$ has not undergone the sharp bend required for entrance into the active site cleft of the enzyme (Murakami et al. 2002; Saecker et al. 2002; Murakami and Darst 2003).

In contrast, DNaseI protection extends to approximately +12 in $\mathrm{RP}_{\mathrm{I}}$, indicating an actual downstream boundary of the complex of approximately +6 , but the strands remain closed. The DNA in the complex displays uniform protection in hydroxyl radical footprints from the -10 hexamer to at least +6 (Supplemental Fig. S4), not the periodic protection observed upstream of the -10 hexamer that is characteristic of binding of RNAP to a single face of the double helix. The hydroxyl radical footprint protection pattern suggests that the DNA duplex in and downstream from the transcription start site is enclosed within the enzyme. Although $r r n B$ P1 RP resembles some other previously reported closed intermediates-e.g., $\lambda \mathrm{P}_{\mathrm{R}} \mathrm{I}_{1}$ (Saecker et al. 2002) and lacUV5 $\mathrm{RP}_{\mathrm{I}}$ (Spassky et al. 1985) - the extent of downstream DNaseI protection in those intermediates was reported to extend further downstream (to at least +20 ).

The DNA duplex in a model of $\lambda \mathrm{P}_{\mathrm{R}} \mathrm{I}_{1}$, an intermediate in $\mathrm{RP}_{\mathrm{O}}$ formation, has an $\sim 90^{\circ}$ bend in the -10 region. In this model, DNA downstream from approximately -5 is enclosed within the enzyme but is positioned $\sim 50 \AA$ above the active site (Saecker et al. 2002). The precise path of duplex DNA in $\lambda \mathrm{P}_{\mathrm{R}} \mathrm{I}_{1}$ (or in $\operatorname{rrnB} \mathrm{P} 1 \mathrm{RP}_{\mathrm{I}}$ ) is not known, but interactions with RNAP in $\lambda P_{R} I_{1}$ were proposed to result in conformational changes leading to a second unstable intermediate, $\mathrm{I}_{2}$. Additional conformational changes were proposed to result in formation of a stable $\mathrm{RP}_{\mathrm{O}}$ (Kontur et al. 2008). $\mathrm{RP}_{\mathrm{I}}$ may be an intermediate immediately preceding $\mathrm{I}_{1}$ in which the clamp has opened to accommodate entry of dsDNA.

We identified multiple substitutions in the RNAP switch regions and $\mathrm{BH}$ that inhibited the transition from $\mathrm{RP}_{\mathrm{C}}$ to $\mathrm{RP}_{\mathrm{I}}$ at $r r n B \mathrm{P} 1$, and thereby mimicked the effects of DksA (Table 1; Figs. 2, 3). In the TEC, most template strand interactions between RNAP and the transcription bubble from approximately -6 to approximately +4 (with respect to the position of the active site) are mediated by residues in the switch regions and $\mathrm{BH}$, whereas duplex DNA downstream from the transcription bubble interacts with the mobile clamp (Gnatt et al. 2001; Vassylyev et al. 2007a). We emphasize that because we do not know the exact path of the DNA in $\mathrm{RP}_{\mathrm{I}}$, we do not know whether the residues identified in our $\Delta d k s A$ suppressor selection directly affect interactions with DNA in $\mathrm{RP}_{\mathrm{I}}$ or indirectly affect interactions with DNA in $\mathrm{RP}_{\mathrm{I}}$ by controlling opening/closing of the clamp domain.

\section{An allosteric model for DksA function}

No structure is available for DksA bound to RNAP, and there is no apparent DksA homolog in Thermus thermophilus or T. aquaticus (Perederina et al. 2004), the only species from which high-resolution bacterial RNAP structures have been solved. However, there is substantial evidence that the coiled-coil tip of DksA is located near the active site and TL in the E. coli RNAP secondary channel: (1) DksA is cleaved when $\mathrm{Mg}^{2+}$ in the active site is replaced by $\mathrm{Fe}^{2+}$ (Figs. 4, 5; Perederina et al. 2004); (2) DksA protects regions of RNAP in the secondary channel near the active site in protein-protein footprints (I. Toulokhonov and R.L. Gourse, unpubl.); and (3) GreB can function like DksA in rRNA regulation when provided at sufficiently high concentrations (Rutherford et al. 2007).

The apparent location of DksA in the RNAP secondary channel and the position of the RNAP-promoter interactions affected by DksA downstream from the -10 region in $\mathrm{RP}_{\mathrm{I}}$ imply that the effects of DksA are allosteric. Effects of substitutions in the TL and the $\mathrm{BH}$ on DksA function suggest that DksA bound in the secondary channel might interact directly with one or both of these structural elements and cause conformational changes that destabilize RNAP-DNA interactions at least 25-40 $\AA$ away (Fig. 6). Possible targets of the conformational changes that are initiated by DksA binding in the secondary channel were suggested by the positions of RNAP substitutions that mimicked the effects of DksA on $\mathrm{RP}_{\mathrm{I}}$, including residues in the switch regions and $\mathrm{BH} . \quad \beta$ G1267V not only mimicked effects of DksA but also eliminated further effects of DksA, suggesting that it might be at/near the end of the pathway for transmission of the effects of DksA to the promoter (Fig. 5). Positions in the switch regions could affect promoter interactions with RNAP through direct interactions with DNA, by 


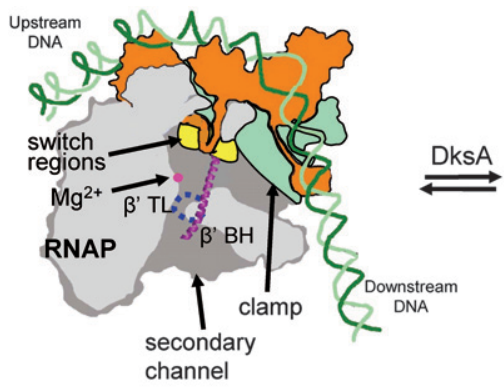

$\mathrm{RP}_{\text {I }}$

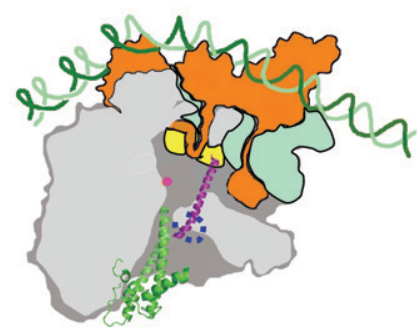

$\mathrm{RP}_{\mathbf{1}}+\mathrm{Dks} \mathrm{A}$

Figure 6. Model for DksA action on $\operatorname{rrnB}$ P1 $\mathrm{RP}_{\mathrm{I}}$. Switch regions (yellow), $\beta^{\prime}$ TL (blue), $\beta^{\prime} \mathrm{BH}$ (purple), downstream clamp (light green), active site $\mathrm{Mg}^{2+}(\mathrm{ma}-$ genta sphere), remainder of RNAP (gray), DksA (dark green). DNA strands are dark green (template) and light green (nontemplate). Schematic model modified by permission from Macmillan Publishers Ltd: Nature Reviews Microbiology (Haugen et al. 2008) (C 2008). (Left) DNA bends toward the active site in the absence of DksA to form $\mathrm{RP}_{\mathrm{I}}$ (downstream boundary of approximately +6 ), with the TL (dotted blue circle) oscillating between multiple conformations. (Right) DksA affects conformation of the TL and $\mathrm{BH}$, ultimately affecting the switch regions. Changes in the switches alter clamp conformation and thereby indirectly affect DNA interactions and/or directly affect DNA contacts. This leads to decreased occupancy of $\mathrm{RP}_{\mathrm{I}}$ and increased occupancy of $\mathrm{RP}_{\mathrm{C}}$ (downstream boundary of approximately -6).

interacting with DNA-binding residues, or by controlling opening/closing of the clamp domain. Understanding the details of the mechanism will depend on the precise interactions between DksA and RNAP, the trajectory of DNA, and the positioning of the RNAP clamp, which are not yet known in $\mathrm{RP}_{\mathrm{I}}$.

We found that the TL is needed for DksA function, consistent with the prediction that the proximity of the TL to the secondary channel could result in regulation of transcription by factors that bind there (Vassylyev et al. $2007 b$ ). Because the substitutions in the $\beta^{\prime}$ TL GG $\rightarrow$ AA ( $\triangle$ SI3) RNAP favor an altered TL conformation (Vassylyev et al. 2007b) and we observed that these substitutions enhanced DksA function (Fig. 4), we suggest that this conformation increases DksA binding and/or more efficiently transmits the effects of DksA binding to the switch regions of RNAP. Effects of DksA also appear to be mediated by the BH (Fig. 5). Thus, the overall picture that emerges is that DksA interacts with certain conformational states of the TL and/or $\mathrm{BH}$ that inhibit $\mathrm{RP}_{\mathrm{I}}$ formation. These TL and/or BH conformations could be a subset of those that occur in core RNAP and that play roles in the NTP addition cycle (Vassylyev et al. 2007b). Interactions of DksA with the TL and/or BH probably form only part of a larger network of interactions contributing to the mechanism of DksA action.

Recently, it was found that the antibiotics myxopyronin, corallopyronin, and ripostatin bind to the RNAP switch regions and inhibit transcription initiation (Belogurov et al. 2008; Mukhopadhyay et al. 2008). Although there was agreement that the antibiotics bound to the switch regions, there was less agreement concerning the mechanism of transcription inhibition. The two models proposed for inhibition by the antibiotics (i.e., antibioticswitch interactions prevent opening of the clamp to allow DNA entry versus antibiotic-switch interactions directly interfere with promoter DNA interactions) are similar to the two potential mechanisms suggested above for the effects of DksA. However, we propose that DksA targets the switch regions allosterically rather than by binding to them directly.

The proximity of the $\mathrm{BH}$ to both the switch regions and the secondary channel and the identification of $\mathrm{BH}$ mutants resistant to DksA support the interpretation that the BH links effects of DksA in the secondary channel to the switch regions. However, we cannot rule out the possibility that the $\Delta d k s A$ suppressor mutations bypass the need for DksA by a completely independent mechanism; i.e., that DksA does not actually affect $\mathrm{RP}_{\mathrm{I}}$ stability by altering the conformation of the switches/BH, even though the end result is the same.

We suggest that the ability of DksA to decrease the lifetimes of complexes formed by all promoters is ascribable to its effects on the $\mathrm{RP}_{\mathrm{C}}$-to- $\mathrm{RP} \mathrm{P}_{\mathrm{I}}$ transition. At promoters that form stable $\mathrm{RP}_{\mathrm{O}}$ complexes, DksA pulls the $\mathrm{RP}_{\mathrm{I}} \leftrightarrow \mathrm{RP}_{\mathrm{O}}$ equilibrium in the dissociation direction, although this does not inhibit transcription initiation because RNAP escapes from the promoter before a major fraction of $\mathrm{RP}_{\mathrm{O}}$ has decayed (Paul et al. 2004; Haugen et al. 2006).

It was proposed previously that DksA might bind to an intermediate between $\mathrm{RP}_{\mathrm{C}}$ and $\mathrm{RP}_{\mathrm{O}}$ and prevent folding of the clamp around downstream promoter DNA (Kontur et al. 2006), a model consistent with the shorter $\mathrm{RP}_{\mathrm{I}}$ footprint that we observed in the presence of DksA. However, our analysis indicates that DksA decreases the lifetime of $R P_{I}$, thereby shifting $R P_{I}$ back to $R P_{C}$, decreasing $\mathrm{RP}_{\mathrm{O}}$ indirectly by reducing occupancy of $\mathrm{RP}_{\mathrm{I}}$ consistent with the absence of effects of DksA on footprints of $\mathrm{RP}_{\mathrm{O}}$ (Supplemental Fig. S2).

\section{Role of ppGpp in DksA function}

Changes in the concentrations of ppGpp and NTPs result in rRNA promoter regulation under different nutritional conditions (Murray et al. 2003). However, modification of RNAP by DksA is required for these small molecules to exert their effects on transcription initiation (Paul et al. 2004, 2005), accounting for large effects of $d k s A$ on regulation in vivo even though its concentration is relatively constant (Rutherford et al. 2007). When DksA concentrations are not saturating, we showed previously that DksA and ppGpp function synergistically (Paul et al. $2004,2005)$. We proposed that together they lower the free energy of an intermediate and/or transition state on the pathway to $\mathrm{RP}_{\mathrm{O}}$ formation, and that differences in the intrinsic kinetics of individual promoters determine 
whether transcriptional output decreases, increases, or stays the same. However, models for the mechanism of ppGpp action and how ppGpp synergizes with DksA await identification of the biologically significant ppGppbinding site on RNAP (Vrentas et al. 2008).

\section{Mechanism of $\Delta d k s$ A suppression}

The basis for the $\Delta d k s A$ auxotrophy (and the suppression of this auxotrophy) could be quite complex. Many cellular promoters require $d k s A$ for regulation (for review, see Magnusson et al. 2007; Haugen et al. 2008), among which are several for amino acid synthesis or transport (Paul et al. 2005). DksA and ppGpp also directly or indirectly affect DNA replication/repair (Trautinger and Lloyd 2002; Trautinger et al. 2005). Consistent with the ability of the $\Delta d k s A$ suppressors to compensate for the absence of amino acids in the growth medium, they increased the activity of at least one amino acid biosynthetic promoter in vivo (Supplemental Fig. S3). However, a subset of the suppressors also increased the activity of the lacUV5 promoter, whose activity with wild-type RNAP is not increased by $\mathrm{DksA} / \mathrm{ppGpp}$. Therefore, further studies will be needed to determine if the mutant RNAPs bypass the loss of $d k s A$ by stimulating amino acid promoter activity.

As indicated above (see also Supplemental Table S3), a relatively small number of the $\Delta d k s A$ suppressors were also isolated as $\Delta$ relA $\Delta$ spoT suppressors in previous selections (e.g., Bartlett et al. 1998; Trautinger and Lloyd 2002; Murphy and Cashel 2003; Szalewska-Palasz et al. 2007). As a further test of the qualitative overlap in the two pools of mutants, we analyzed five mutants isolated only as $\Delta d k s A$ suppressors (indicated with asterisks in Supplemental Table S3) and two additional $\Delta$ relA $\Delta$ spoT suppressors (in rpoD) (Hernandez and Cashel 1995) for their abilities to suppress the nonselected phenotype (see "Expanded Experimental Procedures" in the Supplemental Material). All five $\Delta d k s A$ suppressors suppressed the amino acid auxotrophy of the $\Delta r e l A \Delta s p o T$ mutant, and the two additional $\Delta$ relA $\Delta$ spoT suppressors weakly suppressed the $\Delta d k s A$ mutant (Supplemental Table S3). Therefore, it is possible that all the mutants would (at least weakly) suppress the auxotrophy of the strain in which it was not originally selected.

The absence of complete overlap in the $\Delta r e l A \Delta s p o T$ and $\Delta d k s A$ suppressor sets, and yet their suppression of the other mutant strain when tested, could be explained by the fact that neither selection was saturated: The different suppressor sets could represent different subsets of the same mutant population. However, the different suppressor sets (and their likely differential suppression in quantitative terms of the host strains used for their selection) probably reflect differences in the requirements for DksA and ppGpp for expression of specific target genes (Murray et al. 2003; Paul et al. 2004; Magnusson et al. 2007) or for maintaining genome integrity (Trautinger et al. 2005). In this regard, we note that different selections or screens were used in some cases for mutant identification (Trautinger and Lloyd 2002; Szalewska-Palasz et al. 2007).

\section{Future prospects}

We have presented a model for the mechanism of DksA function in transcription initiation. Although our model can explain the basic elements of negative regulation, we still lack a structural framework for understanding how the same conformational changes could lead to positive control of transcription initiation and for understanding the mechanism of DksA synergy with ppGpp. Additional studies will be needed to expand on the basic framework provided here.

\section{Materials and methods}

Strains, plasmids, and primers

Strains, plasmids, and primers are listed in Supplemental Tables S1 and S4.

\section{RNAP and DksA purification}

Wild-type and mutant RNAPs were purified as described in the Supplemental Material. The methods produced enzymes that responded to DksA and ppGpp identically (Vrentas et al. 2005). His $_{6}$-tagged DksA was purified as described (Paul et al. 2004).

\section{DNaseI and $\mathrm{KMnO}_{4}$ footprinting}

DNaseI and $\mathrm{KMnO}_{4}$ footprints were performed essentially as described (Newlands et al. 1991; Bartlett et al. 1998). PhosphorImager traces were obtained by quantifying each lane, normalizing to a region of the DNA not affected by RNAP or DksA. Footprints were performed multiple times, and representative gels are shown. See the Supplemental Material for details.

Selection, mapping, and identification

of $\Delta d k s$ A suppressor mutations

See "Expanded Experimental Procedures" in the Supplemental Material for details. Briefly, a $\Delta d k s A$ strain was plated on a medium lacking amino acids at $30^{\circ} \mathrm{C}$. Colonies $(\Delta d k s A$ suppressors) appeared after $\sim 2 \mathrm{~d}$ at a frequency of $\sim 10^{-5}$ or $10^{-6}$. All 67 suppressor mutations tested were linked to rpoBC. The $r p o B C$ region was amplified from 52 suppressor strains by PCR of 10 overlapping portions of each gene, using the primers listed in Supplemental Table S4, and sequenced with the same primers. Mutations were identified in 49 strains (Table 1; the strain numbers are in Supplemental Table S2).

\section{Promoter activity assays}

Promoter activities were determined in vivo by measuring $\beta$ galactosidase activities produced from $\operatorname{rrnB}$ P1/endpoints -61 , +1 )-lacZ fusions (Barker et al. 2001a) from cells grown at $30^{\circ} \mathrm{C}$ in MOPS medium with $0.4 \%$ glycerol and $40 \mu \mathrm{g} / \mathrm{mL}$ each of tryptophan and tyrosine and $80 \mu \mathrm{g} / \mathrm{mL}$ each of the other 18 amino acids. Promoter activities were determined in vitro from multiple round transcription reactions (Barker et al. 2001a; Rutherford et al. 2007). Supercoiled plasmid templates contained the RNA1 promoter (used as a control) and either the $\operatorname{rrnB} \mathrm{P} 1$ promoter $(-66,+50)$ or the $\operatorname{argI}$ promoter $(-45,+32)$. Transcripts were separated on gels and analyzed by PhosphorImaging. DksA $(2 \mu \mathrm{M})$, ppGpp $(100 \mu \mathrm{M})$, or both were included when indicated.

\section{RNAP-promoter complex decay assays}

Competitor-resistant complex lifetimes were measured as described previously by either nitrocellulose filter retention or 
using in vitro transcription as a readout (Barker et al. 2001a; Rutherford et al. 2007). The competitor was heparin $(10 \mu \mathrm{g} / \mathrm{mL})$. Details are provided in the Supplemental Material and in the figure legends.

\section{Localized $\mathrm{Fe}^{2+}$-mediated cleavage of HMK-labeled DksA}

Radiolabeled HMK-His ${ }_{6}$-tagged DksA was incubated with RNAP at $37^{\circ} \mathrm{C}$, mixed with freshly prepared $500 \mu \mathrm{M}\left(\mathrm{NH}_{4}\right)_{2} \mathrm{Fe}\left(\mathrm{SO}_{4}\right)_{2}$ and $100 \mathrm{mM}$ DTT for $15 \mathrm{~min}$ at $37^{\circ} \mathrm{C}$, and quenched with loading buffer. Reactions were separated by PAGE. See the Supplemental Material for details.

\section{Acknowledgments}

We thank R. Ebright, R. Landick, T. Record, and R. Saecker for comments on the manuscript; I. Toulokhonov for sharing protocols and unpublished data; R. Landick and M. Cashel for strains; J. Zhang and P. Chandrangsu for RNAP preparations; and T. Gaal for help with the figures. This work was supported by R37 GM37048 from the National Institutes of Health to R.L.G., by predoctoral fellowships from the NIH and the Department of Bacteriology to S.T.R., and by a post-doctoral fellowship from the Korean Research Foundation to J.-H.L.

\section{References}

Barker, M.M., Gaal, T., Josaitis, C.A., and Gourse, R.L. 2001a. Mechanism of regulation of transcription initiation by ppGpp. I. Effects of ppGpp on transcription initiation in vivo and in vitro. J. Mol. Biol. 305: 673-688.

Barker, M.M., Gaal, T., and Gourse, R.L. 2001b. Mechanism of regulation of transcription initiation by ppGpp. II. Models for positive control based on properties of RNAP mutants and competition for RNAP. J. Mol. Biol. 305: 689-702.

Bartlett, M.S., Gaal, T., Ross, W., and Gourse, R.L. 1998. RNA polymerase mutants that destabilize RNA polymerasepromoter complexes alter NTP-sensing by rrn P1 promoters. J. Mol. Biol. 279: 331-345.

Belogurov, G.A., Vassylyeva, M.N., Sevostyanova, A., Appleman, J.R., Xiang, A.X., Lira, R., Webber, S.E., Klyuyev, S., Nudler, E., Artsimovitch, I., et al. 2008. Transcription inactivation through local refolding of the RNA polymerase structure. Nature doi: 10.1038/nature07510.

Bokal IV, A.J., Ross, W., and Gourse, R.L. 1995. The transcriptional activator protein FIS: DNA interactions and cooperative interactions with RNA polymerase at the Escherichia coli rrnB P1 promoter. J. Mol. Biol. 245: 197-207.

Borukhov, S., Sagitov, V., Josaitis, C., Gourse, R.L., and Goldfarb, A. 1993. Two modes of transcription initiation in vitro at the rrnB P1 promoter of Escherichia coli. J. Biol. Chem. 268: $23477-23482$.

Cowing, D.W., Mecsas, J., Record, M.T., and Gross, C.A. 1989. Intermediates in the formation of the open complex by RNA polymerase holoenzyme containing the $\sigma$ factor $\sigma^{32}$ at the groE promoter. J. Mol. Biol. 210: 521-530.

Cramer, P., Bushnell, D.A., and Kornberg, R.D. 2001. Structural basis of transcription: RNA polymerase II at 2.8 angstrom resolution. Science 292: 1863-1876.

Gnatt, A.L., Cramer, P., Fu, J., Bushnell, D.A., and Kornberg, R.D. 2001. Structural basis of transcription: An RNA polymerase II elongation complex at $3.3 \AA$ A resolution. Science 292: $1876-1882$.

Gourse, R.L. 1988. Visualization and quantitative analysis of complex formation between $E$. Coli RNA polymerase and an rRNA promoter in vitro. Nucleic Acids Res. 16:: 97899809.
Haugen, S.P., Berkmen, M.B., Ross, W., Gaal, T., Ward, C., and Gourse, R.L. 2006. rRNA promoter regulation by nonoptimal binding of $\sigma$ region 1.2: An additional recognition element for RNA polymerase. Cell 125: 1069-1082.

Haugen, S.P., Ross, W., and Gourse, R.L. 2008. Advances in bacterial promoter recognition and its control by factors that do not bind DNA. Nat. Rev. Microbiol. 6: 507-519.

Hernandez, V.J. and Cashel, M. 1995. Changes in conserved region 3 of Escherichia coli $\sigma^{70}$ mediate ppGpp-dependent functions in vivo. J. Mol. Biol. 252: 536-549.

Kontur, W.S., Saecker, R.M., Davis, C.A., Capp, M.W., and Record, M.T. 2006. Solute probes of conformational changes in open complex (RPo) formation by Escherichia coli RNA polymerase at the $\lambda \mathrm{P}_{\mathrm{R}}$ promoter: Evidence for unmasking of the active site in the isomerization step and for large-scale coupled folding in the subsequent conversion to $\mathrm{RP}_{\mathrm{O}}$. Biochemistry 45: 2161-2177.

Kontur, W.S., Saecker, R.M., Capp, M.W., and Record, M.T. 2008. Late steps in the formation of $E$. coli RNA polymerase$\lambda \mathrm{P}_{\mathrm{R}}$ promoter open complexes: Characterization of conformational changes by rapid [perturbant] upshift experiments. J. Mol. Biol. 376: 1034-1047.

Lawson, C.L., Swigon, D., Murakami, K.S., Darst, S.A., Berman, H.M., and Ebright, R.H. 2004. Catabolite activator protein: DNA binding and transcription activation. Curr. Opin. Struct. Biol. 14: 10-20.

Magnusson, L.U., Gummesson, B., Joksimovic, P., Farewell, A., and Nystrom, T. 2007. Identical, independent, and opposing roles of ppGpp and DksA in Escherichia coli. J. Bacteriol. 189: 5193-5202.

Mukhopadhyay, J., Das, K., Ismail, S., Koppstein, D., Jang, M., Hudson, B., Sarafianos, S., Tuske, S., Patel, J., Jansen, R., et al. 2008. Myxopyronin, corrallopyronin, and ripostatin inhibit transcription by binding to the RNA polymerase "switch region." Cell 135: 295-307.

Murakami, K.S. and Darst, S.A. 2003. Bacterial RNA polymerases: The wholo story. Curr. Opin. Struct. Biol. 13: 3139.

Murakami, K.S., Masuda, S., Campbell, E.A., Muzzin, O., and Darst, S.A. 2002. Structural basis of transcription initiation: An RNA polymerase holoenzyme-DNA complex. Science 296: $1285-1290$.

Murphy, H. and Cashel, M. 2003. Isolation of RNA polymerase suppressors of a (p)ppGpp deficiency. Methods Enzymol. 371: 596-601.

Murray, H.D., Schneider, D.A., and Gourse, R.L. 2003. Control of rRNA expression by small molecules is dynamic and nonredundant. Mol. Cell 12: 125-134.

Newlands, J.T., Ross, W., Gosink, K.K., and Gourse, R.L. 1991. Factor-independent activation of Escherichia coli rRNA transcription. II. Characterization of complexes of $\operatorname{rrnB}$ P1 promoters containing or lacking the upstream activator region with Escherichia coli RNA polymerase. J. Mol. Biol. 220: $569-583$.

Opalka, N., Chlenov, M., Chacon, P., Rice, W.J., Wriggers, W., and Darst, S.A. 2003. Structure and function of the transcription elongation factor GreB bound to bacterial RNA polymerase. Cell 114: 335-345.

Paul, B.J., Barker, M.M., Ross, W., Schneider, D.A., Webb, C., Foster, J.W., and Gourse, R.L. 2004. DksA: A critical component of the transcription initiation machinery that potentiates the regulation of rRNA promoters by ppGpp and the initiating NTP. Cell 118: 311-322.

Paul, B.J., Berkmen, M.B., and Gourse, R.L. 2005. DksA potentiates direct activation of amino acid promoters by ppGpp. Proc. Natl. Acad. Sci. 102: 7823-7828. 
Perederina, A., Svetlov, V., Vassylyeva, M.N., Tahirov, T.H., Yokoyama, S., Artsimovitch, I., and Vassylyev, D.G. 2004. Regulation through the secondary channel-structural framework for ppGpp-DksA synergism during transcription. Cell 118: 297-309.

Rutherford, S.T., Lemke, J.J., Vrentas, C.E., Gaal, T., Ross, W., and Gourse, R.L. 2007. Effects of DksA, GreA, and GreB on transcription initiation: Insights into the mechanisms of factors that bind in the secondary channel of RNA polymerase. J. Mol. Biol. 366: 1243-1257.

Saecker, R.M., Tsodikov, O.V., McQuade, K.L., Schlax, P.E., Capp, M.W., and Record, M.T. 2002. Kinetic studies and structural models of the association of E. coli $\sigma^{70}$ RNA polymerase with the $\lambda \mathrm{P}(\mathrm{R})$ promoter: Large scale conformational changes in forming the kinetically significant intermediates. J. Mol. Biol. 319: 649-671.

Schickor, P., Metzger, W., Werel, W., Lederer, H., and Heumann, H. 1990. Topography of intermediates in transcription initiation of E. coli. EMBO J. 9: 2215-2220.

Spassky, A., Kirkegaard, K., and Buc, H. 1985. Changes in the DNA structure of the lacUV5 promoter during formation of an open complex with Escherichia coli RNA polymerase. Biochemistry 24: 2723-2731.

Suck, D. and Oefner, C. 1986. Structure of DNase I at $2.0 \AA$ resolution suggests a mechanism for binding to and cutting DNA. Nature 321: 620-625.

Szalewska-Palasz, A., Johansson, L.U., Bernardo, L.M., Skarfstad, E., Stec, E., Brannstrom, K., and Shingler, V. 2007. Properties of RNA polymerase bypass mutants: Implications for the role of ppGpp and its co-factor DksA in controlling transcription dependent on $\sigma^{54}$. J. Biol. Chem. 282: 18046-18056.

Toulokhonov, I., Zhang, J., Palangat, M., and Landick, R. 2007. A central role of the RNA polymerase trigger loop in active-site rearrangement during transcriptional pausing. Mol. Cell 27: 406-419.

Trautinger, B.W. and Lloyd, R.G. 2002. Modulation of DNA repair by mutations flanking the DNA channel through RNA polymerase. EMBO J. 21: 6944-6953.

Trautinger, B.W., Jaktaji, R.P., Rusakova, E., and Lloyd, R.G. 2005. RNA polymerase modulators and DNA repair activities resolve conflicts between DNA replication and transcription. Mol. Cell 19: 247-258.

Vassylyev, D.G., Sekine, S., Laptenko, O., Lee, J., Vassylyeva, M.N., Borukhov, S., and Yokoyama, S. 2002. Crystal structure of a bacterial RNA polymerase holoenzyme at $2.6 \AA$ resolution. Nature 417: 712-719.

Vassylyev, D.G., Vassylyeva, M.N., Perederina, A., Tahirov, T.H., and Artsimovitch, I. 2007a. Structural basis for transcription elongation by bacterial RNA polymerase. Nature 448: 157-162.

Vassylyev, D.G., Vassylyeva, M.N., Zhang, J., Palangat, M., Artsimovitch, I., and Landick, R. 2007b. Structural basis for substrate loading in bacterial RNA polymerase. Nature 448: 163-168.

Vrentas, C.E., Gaal, T., Ross, W., Ebright, R.H., and Gourse, R.L. 2005. Response of RNA polymerase to ppGpp: Requirement for the $\omega$ subunit and relief of this requirement by DksA. Genes \& Dev. 19: 2378-2387.

Vrentas, C.E., Gaal, T., Berkmen, M.B., Rutherford, S.T., Haugen, S.P., Vassylyev, D., Ross, W., and Gourse, R.L. 2008. Still looking for the magic spot: The crystallographically defined binding site for ppGpp on RNA polymerase is unlikely to be responsible for rRNA transcription regulation. J. Mol. Biol. 377: 551-564.

Zhou, Y.N. and Jin, D.J. 1998. The rроB mutants destabilizing initiation complexes at stringently controlled promoters behave like "stringent" RNA polymerases in Escherichia coli. Proc. Natl. Acad. Sci. 95: 2908-2913. 


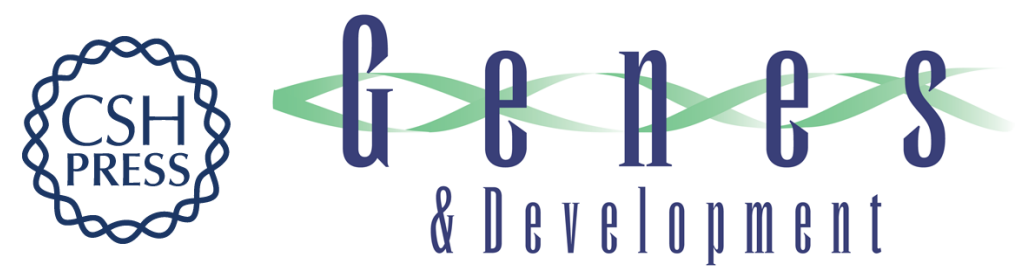

\section{Allosteric control of Escherichia coli rRNA promoter complexes by DksA}

Steven T. Rutherford, Courtney L. Villers, Jeong-Hyun Lee, et al.

Genes Dev. 2009, 23:

Access the most recent version at doi:10.1101/gad.1745409

\section{Supplemental http://genesdev.cshlp.org/content/suppl/2009/01/27/23.2.236.DC1 \\ Material}

Related Content Promoter-specific control of E. coli RNA polymerase by ppGpp and a general transcription factor

Jeffrey W. Roberts

Genes Dev. January , 2009 23: 143-146

References This article cites 41 articles, 9 of which can be accessed free at: http://genesdev.cshlp.org/content/23/2/236.full.html\#ref-list-1

Articles cited in:

http://genesdev.cshlp.org/content/23/2/236.full.html\#related-urls

\section{License}

Email Alerting

Service

Receive free email alerts when new articles cite this article - sign up in the box at the top right corner of the article or click here.

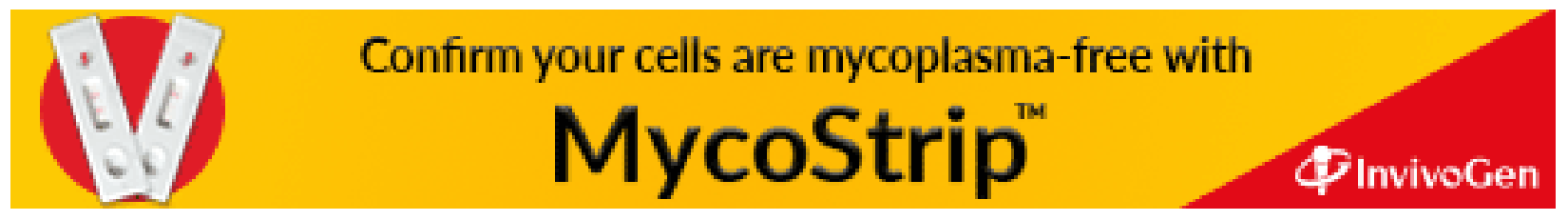

